\title{
Radiological diagnosis of perinephric pathology: pictorial essay 2015
}

\author{
${\text { Goran } \text { Mitreski }^{1} \cdot \text { Tom Sutherland }}^{2}$
}

Received: 6 June 2016 / Revised: 14 November 2016 / Accepted: 23 November 2016 / Published online: 3 January 2017

(C) The Author(s) 2017. This article is published with open access at Springerlink.com

\begin{abstract}
The perinephric space, shaped as an inverted cone, sits between the anterior and posterior renal fasciae. It can play host to a variety of clinical conditions encountered daily in the reporting schedule for a radiologist. Lesions may be classified and diagnosed based on their imaging characteristics, location and distribution. A broad range of differential diagnoses can be attributed to pathology sitting within this space, often without clinical signs or symptoms. An understanding of commonly encountered conditions affecting the perinephric space, along with characteristic imaging findings, can illustrate and often narrow the likely diagnosis. The aim of this essay is to describe commonly encountered neoplastic and nonneoplastic entities involving the perinephric space and to describe their key imaging characteristics.
\end{abstract}

\section{Teaching Point}

- Despite often a bulky disease, perinephric lymphoma does not produce obstruction or stenosis.

- In primarily fatty masses, defects within the renal capsule likely represent angiomyolipoma.

- Consider paraganglioma if biopsy is planned; biopsy may lead to catecholamine crisis.

Goran Mitreski

g_mitreski@hotmail.com

Tom Sutherland

tom.sutherland@svhm.org.au

1 University Hospital Geelong, Bellarine Street, 3220 Geelong, Australia

2 Medical Imaging Department, St Vincent's Hospital, 41 Victoria Pde, 3065 Fitzroy, Australia
Keywords Kidney · Neoplasms, connective and soft tissue · Tomography, spiral computed · Magnetic resonance imaging . Perinephric space

$\begin{array}{ll}\text { Abbreviations } \\ \text { CT } & \text { Computed tomography } \\ \text { MRI } & \text { Magnetic resonance imaging } \\ \text { PET } & \text { Positron emission tomography } \\ \text { APPFC } & \text { Acute peripancreatic fluid collection } \\ \text { AML } & \text { Angiomyolipoma } \\ \text { SFT } & \text { Solitary fibrous tumour } \\ \text { PCC } & \text { Phaeochromocytoma } \\ \text { I-MIBG } & { }^{123} \text { meta-iodobenzylguanide } \\ \text { FDG } & {\left[{ }^{18} \text { F]fluorodeoxy-D-glucose }\right.} \\ \text { F-FDOPA } & 6 \text { - }\left[{ }^{18} \text { F]L-fluoro-L-3,4-dihydroxyphenylalanine }\right. \\ \text { EGIST } & \text { Extra-gastrointestinal stromal tumour }\end{array}$

\section{Introduction}

A diverse assortment of pathologies can present within the perinephric space. The aetiology of disorders seen on radiological imaging can be attributed to solid tumours, both benign and malignant; fluid collections; inflammatory masses; or proliferative syndromes. Appreciation of the close relationship between the perinephric space and adjacent retroperitoneal organs and planes can assist in localising the site of origin of pathologies and can help narrow the differential diagnosis. An understanding of the imaging characteristics of these pathologies will then enable a more accurate diagnosis and guidance of treatment.

This pictorial essay will review and illustrate conditions commonly encountered within the perinephric space, 
outlining relevant anatomical landmarks, radiological signs and features, along with patterns of disease spread.

\section{Anatomical landmarks}

Basic knowledge and understanding of the retroperitoneal anatomical spaces is essential to understanding disease presentation and patterns of spread. The retroperitoneum is divided into three distinct compartments: the perinephric space, anterior pararenal space and posterior pararenal space [1] (Fig. 1).

The perinephric space is formed by adjacent bordering pararenal spaces anteriorly and posteriorly. The perinephric space contains the kidneys, proximal ureters, adrenal glands, fat, bridging septa (Kunin's septa), vessels and lymphatics [2]. The thin lamina anteriorly, also known as Gerota's fascia, fuses with the thicker posterior Zuckerkandl's fascia to form the lateral lateroconal fascia. Medially, the perinephric fascial extension joins the periureteral connective tissue and duodenal attachments on the right, whilst on the left its attachment is seen to extend towards the periaortocaval connective tissue. Superiorly, it attaches to the diaphragm, whilst it continues and attaches to the iliac fascia inferiorly as a combined inter-fascial plane [3].

The perinephric space appears as an inverted cone, corresponding to the embryological migration of the renal system from the pelvis [4] (Figs. 2 and 3).
The pararenal spaces lie superficial to the perinephric space. The anterior pararenal space lies between the parietal peritoneum and Gerota's fascia, and contains the pancreas, duodenum, and ascending and descending colon. The posterior pararenal space sits between Zuckerkandl's fascia and the transversalis fascia, and contains no organs, only fat pads. As the inter-fascial plane continues towards the iliac fascia, the space produced between Gerota's fascia and Zuckerkandl's fascia is known as the infrarenal space $[1,3]$.

As the perinephric space lies centrally in the retroperitoneal space, disease manifestation and transmission of pathology, such as that of malignancy, can traverse fascial planes, as can rapidly accumulating fluid collections [2]. Slowly accumulating fluids are usually confined to their compartment of origin.

\section{Non-neoplastic}

\section{Blood}

A perinephric haematoma is typically described as fluid that is confined within the dense, collagenous Gerota's fascia [5]. Traumatic causes include both blunt and penetrating injury, while iatrogenic causes include renal biopsy, ablation, nephrostomy and lithotripsy complications. These causes are typically distinguishable by the clinical setting or the presence

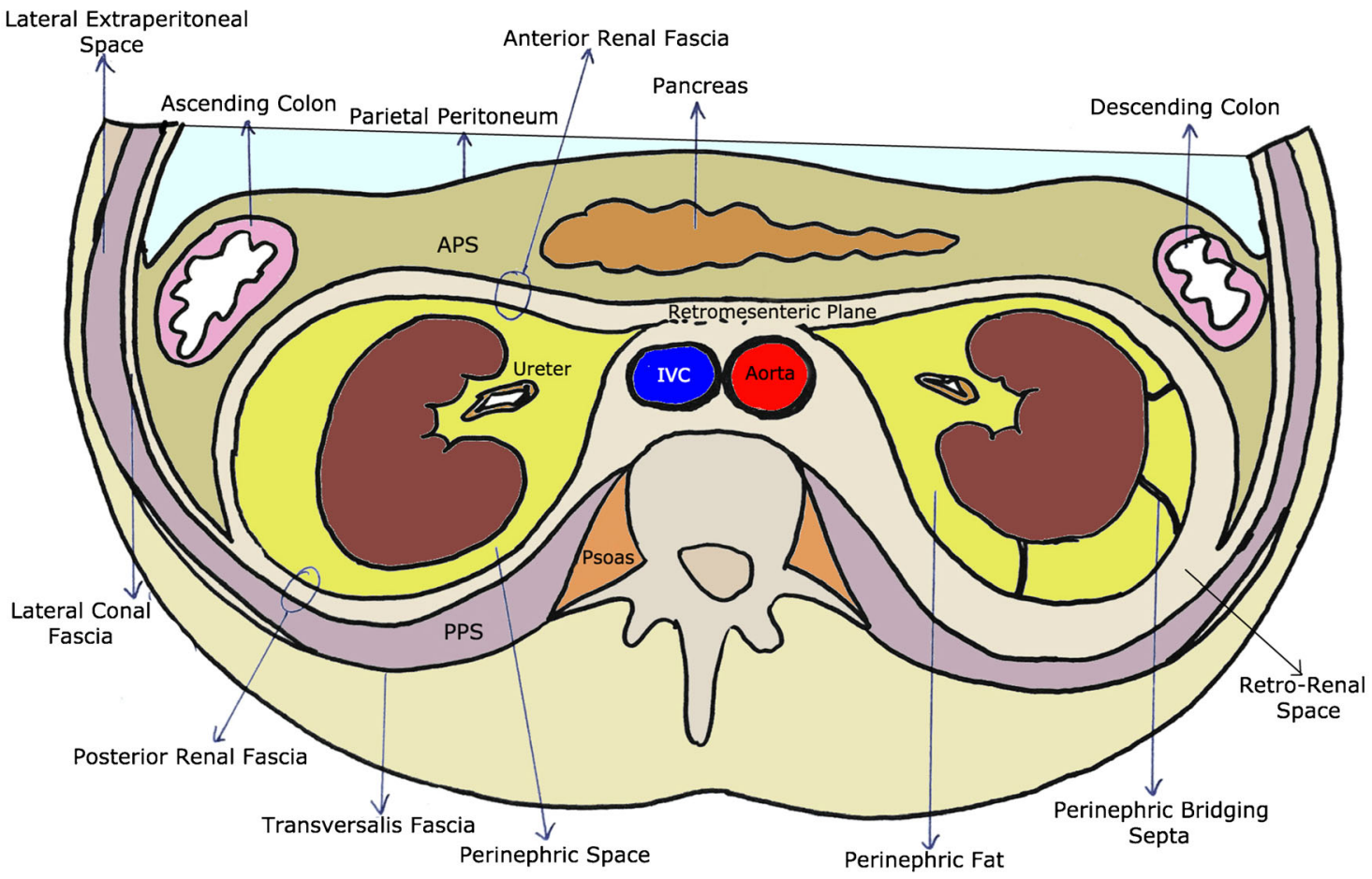

Fig. 1 Diagrammatic representation of the perinephric space. The posterior pararenal space (PPS) and anterior pararenal space (APS) have been exaggerated to provide representation of their relation to other retroperitoneal structures. Perinephric bridging septa are seen between the left kidney and the adjacent renal fascia 


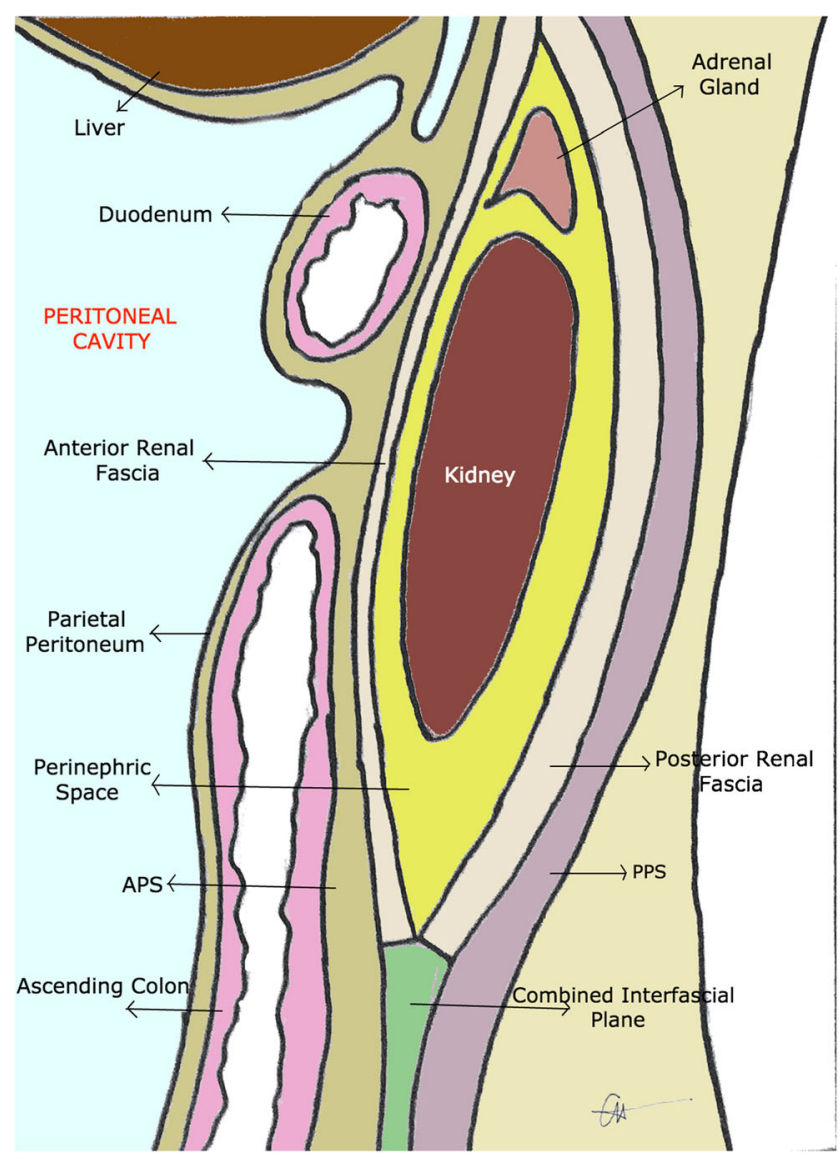

Fig. 2 Lateral longitudinal representation of the perinephric space. The adrenal gland lies within the perinephric space, superior to the kidney. The anterior renal fascia and posterior renal fascia join inferiorly into the pelvis as the combined inter-fascial plane

of coexisting injuries such as splenic or hepatic lacerations [6]. Spontaneous bleeding can occur in hypo-coagulable states,

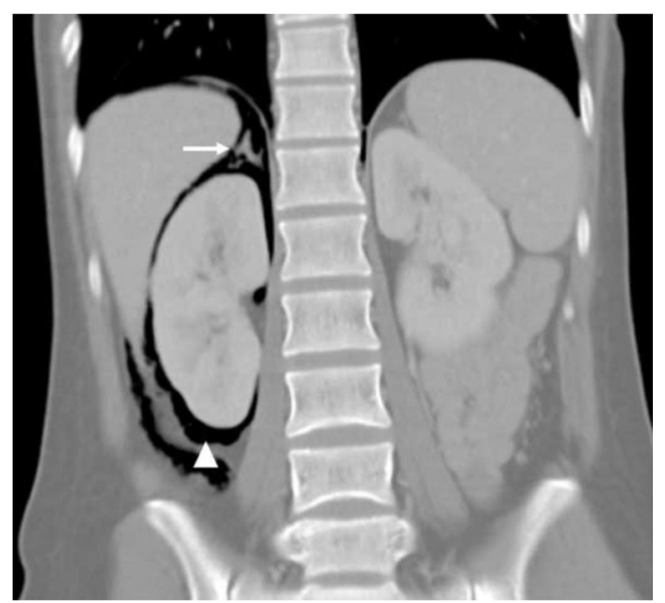

Fig. 3 Conal portal venous CT shows gas in the perinephric space (arrowhead), demonstrating its longitudinal conal orientation and that it contains both the kidney and the adrenal (arrow). The gas was secondary to a perforation during colonoscopy but is more frequently a complication of primary renal neoplasms such as angiomyolipoma or renal cell carcinoma. A bleeding tumour can usually be easily identified with crosssectional imaging, although a small lesion may occasionally be obscured by the haematoma in the acute setting. In these cases, follow-up will be required to re-examine the kidney once the haematoma involutes. Angiomyolipomas can be differentiated from renal cell carcinoma based upon the presence of macroscopic fat within them, and their haemorrhagic risk is greatest when they are over $4 \mathrm{~cm}$ in size [7]. Spontaneous bleeding can also occur secondary to polyarteritis nodosa, vascular malformations or aneurysms arising from the renal arteries or from the abdominal aorta [8].

Acute haematoma has a higher attenuation value than renal parenchyma on unenhanced CT imaging (Fig. 4a) and a lower attenuation value on contrast-enhanced imaging (Fig. 4b). Active bleeding can be detected using multiphase CT. Subacute haematomas have a Hounsfield density closer to that of water $(0$ to $+20 \mathrm{HU})$ secondary to haematoma liquefaction, and occasionally a fluid level can be appreciated with the denser element being dependent $[8,9]$. The aetiology of haematoma formation is outlined in Table $1[10,11]$.

\section{Urine}

Urine leaks are most frequently secondary to trauma (Fig. 5), either blunt or penetrating, and most often arise proximally from the calyces or renal pelvis, and therefore present as fluid within the perinephric space [12]. These points of relative weakness are also the sites of rupture when obstructive back pressure is the cause of system rupture. The primary site of obstruction may be more distally located in the urinary system and may relate to calculi, retroperitoneal fibrosis, pregnancy or other pelvic masses. Iatrogenic causes are recognised but are relatively uncommon except for ureteral injuries, with the site of leak relating to the site of ureteral intervention/injury [13]. Urine on contrast-enhanced CT has a Hounsfield unit (HU) nearing that of water $(0$ to +10$)$, identical to other simple
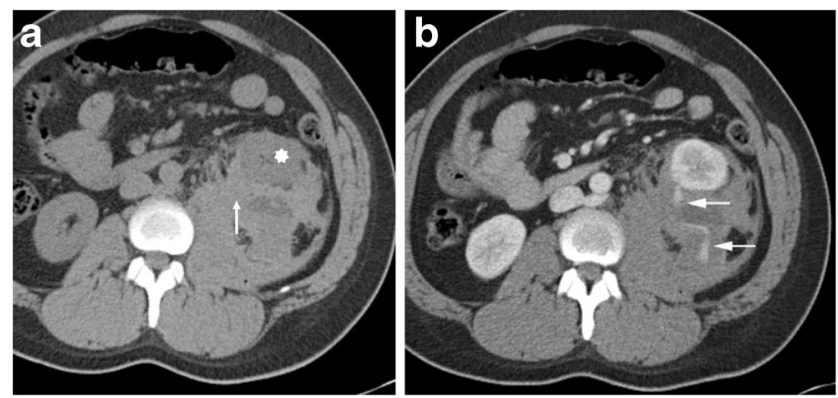

Fig. 4 a Acute left-sided haematoma that is isodense to muscle (arrow), displacing the kidney anteriorly (star). b The portal venous phase shows active bleeding (arrows) into the haematoma. The bleed was secondary to an ultrasound-guided biopsy 
Table 1 Aetiology of perinephric haematoma

\begin{tabular}{ll}
\hline Traumatic & Blunt trauma \\
& Penetrating injury \\
Renal biopsy & Surgery: nephron-sparing/partial \\
nephrectomy \\
Nephrostomy insertion \\
Ablation \\
Lithotripsy \\
Bleeding diathesis (hepatic failure, \\
haemophilia, systemic lupus \\
erythematosus, thrombocytopaenia) \\
medication-related \\
Vascular disease (ANCA \\
vasculitis, Behçet's disease, arterial \\
venous malformation) \\
Renal tumours (angiomyolipoma, \\
renal cell cancer, renal metastases) \\
Renal infarction (emphysematous \\
pyelonephritis, abscess) \\
Adrenal haemorrage (sepsis, burns, \\
complicated pregnancy) \\
Renal cysts
\end{tabular}

fluid collections. Delayed-phase contrast CT can show extravasation of urine (Fig. 6), allowing accurate differentiation from other fluid collections, and multiplanar reformations can aid in identifying the precise site of urine leak (Fig. 7). Alternatively, in patients with renal impairment precluding the use of intravenous contrast, renal scintigraphy can be used to demonstrate communication between the renal collecting system and the perinephric fluid, albeit with reduced spatial resolution. It is important to remember to inspect the entire urinary system to identify the primary cause of leakage, especially in cases secondary to ureteral obstruction. In cases of

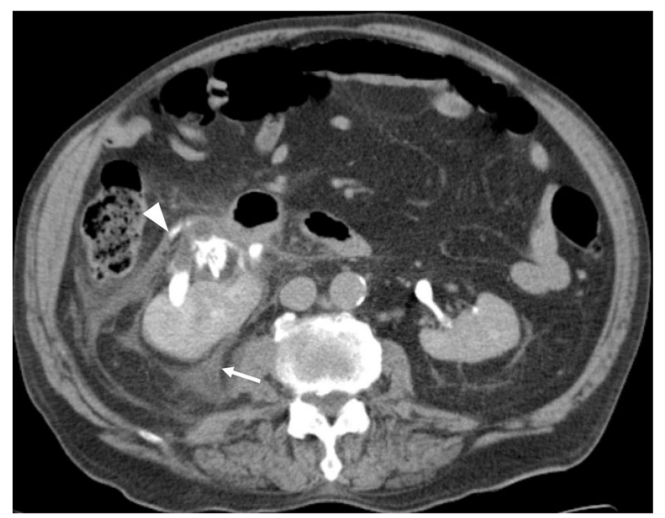

Fig. 5 Delayed-phase CT in a patient with calyceal rupture following lithotripsy shows fluid in the perinephric space (arrow) and extravasation of contrast (arrowhead) in keeping with active urine leak

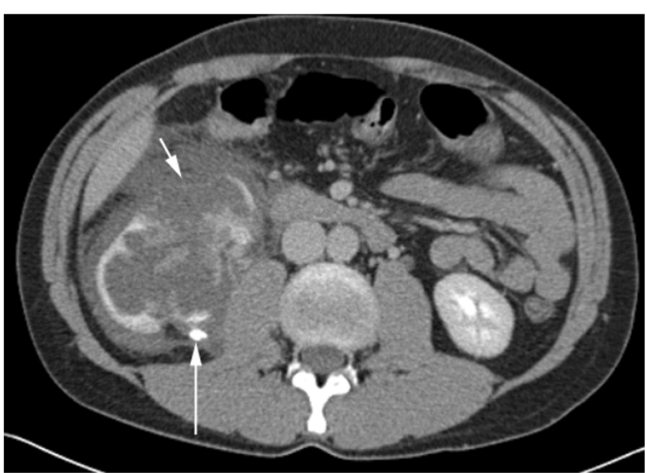

Fig. 6 Delayed-phase CT shows fluid filling the right perinephric space in a patient following blunt trauma. The kidney has been lacerated (short arrow), and urinary contrast extravasation is shown posteriorly (long arrow)

diagnostic dilemma, fine needle aspiration with measurement of fluid creatinine can be diagnostic [3].

The transition of acute urinary extravasation to chronic urinoma formation is secondary to encapsulated urine that leaks and collects within the boundaries of the anterior and posterior renal fascia, producing a proinflammatory and fibrosing state. A urinoma may present with gross fibrous thickening and an enhancing rim and septa on contrastenhanced CT [3].

\section{Lymph}

Lymphangiomas are congenital benign cystic tumours that most frequently occur within the neck, although up to 5\% occur within the abdominal cavity, with the mesentery and retroperitoneum the most common abdominal sites $[14,15]$. When small, they are asymptomatic, often diagnosed as an incidental finding during imaging examinations for other indications (Fig. 8a). When large, they can present with mass effect due to compression of adjacent organs, and similar to

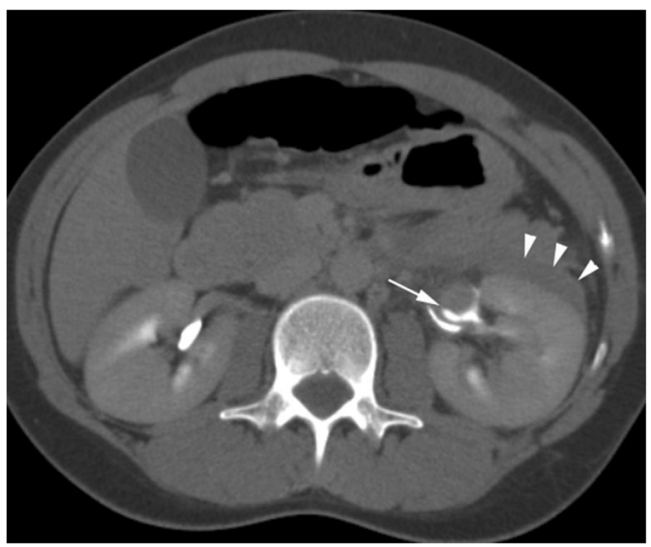

Fig. 7 A delayed-phase CT shows a left renal pelvis with extravasation of urine anterior to it (arrow). Note the unopacified urine in the perinephric space (arrowheads) 
their cervical counterparts can be trans-spatial. Lymphangiomas comprise a series of dilated cystic spaces that contain fluids such as chyle, blood products from previous haemorrhage, serous fluid or a mixture. The fluid typically outlines the thin enhancing walls of the cystic spaces, and at MRI, the lesions follow fluid signal intensity on all acquisitions unless complicated by blood product or superimposed infection [16] (Fig. 8b). Elevated apparent diffusion coefficient (ADC) values are also typical.

Sonographically, the lesions appear as anechoic fluid divided by thin-walled septa (Fig. 9), with no appreciable flow on Doppler imaging. Differentiation from other fluid collections can be difficult, as can diagnosing superimposed infection. Aspiration typically yields a milky white fluid, with elevated triglyceride level [17].

Renal lymphangiomatosis is a rare condition of unknown aetiology. It is believed to arise secondary to poor renal lymphatic communication during embryological development. It is characterised by small peri-pelvic and capsular cystic changes that may be uni- or multilocular. The imaging appearance is similar to lymphangiomas, apart from the location as a subcapsular pathology rather than arising within the perinephric space. The condition may be unilateral or bilateral. It can occur at any age and has no predilection for sex. Diagnosis tends to focus on histology, as radiological signs are often indeterminate for lymphangioma [18]. Treatment is usually conservative yet percutaneous drainage or surgical marsupialiation is warranted if fluid shifts and fluid expansion cause mass effect $[19,20]$.

\section{Pseudocyst}

Acute pancreatitis is accompanied by fluid collections in around $43 \%$ of cases [21], with risk factors including alcohol-induced pancreatitis, younger age and severe pancreatitis [6, 22]. Acute peripancreatic fluid collections (APPFCs) occur in the early phase of pancreatitis, may be multiple, are
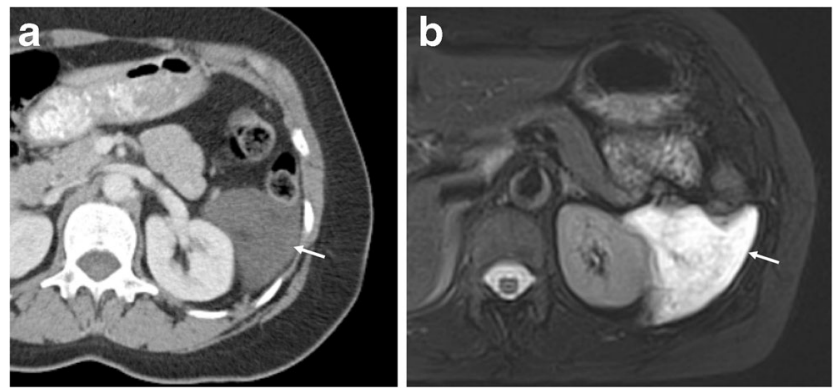

Fig. 8 a A well-defined and fluid attenuation homogeneous cystic lymphangioma in the left perirenal space (arrow), with no capsule and no evidence of mass effect on the adjacent kidney. b A T2-weighted MRI shows the fluid signal of the lesion (arrow)

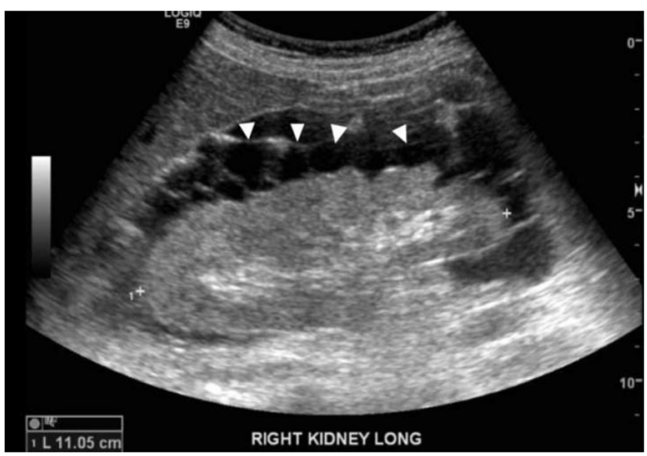

Fig. 9 Ultrasound image showing multiple subcapsular cystic lesions (arrowheads) bulging into the perinephric space outlining the entire kidney in a patient with lymphangiectasia

typically sterile and usually spontaneously resolve [23]. When present for over 4 weeks, they become known as pseudocysts. Pseudocyst formation occurs in $5-15 \%$ of patients following acute pancreatitis $[21,24]$. The collections are homogenous and of fluid density/intensity, and with time can develop smoothly enhancing margins. Imaging will show a rounded or oval fluid-filled collection without any internal septa or non-liquefied components (Fig. 10). The presence of debris and heterogeneity indicates complexity and that the area is an acute necrotic collection/walled-off necrosis, with these lesions usually confined to the anterior pararenal space. Aspiration of APPFCs or pseudocysts reveals elevated levels of amylase [25].

In $40-69 \%$ of pseudocysts, a communication will remain with the pancreatic duct [26]. MR cholangiopancreatography is more accurate than contrast-enhanced $\mathrm{CT}$ at depicting this residual ductal communication; endoscopic retrograde cholangiopancreaticography (ERCP) remains the gold standard for diagnosis [27]. MRI can also demonstrate blood product within a collection when haemorrhagic transformation is a concern [28].

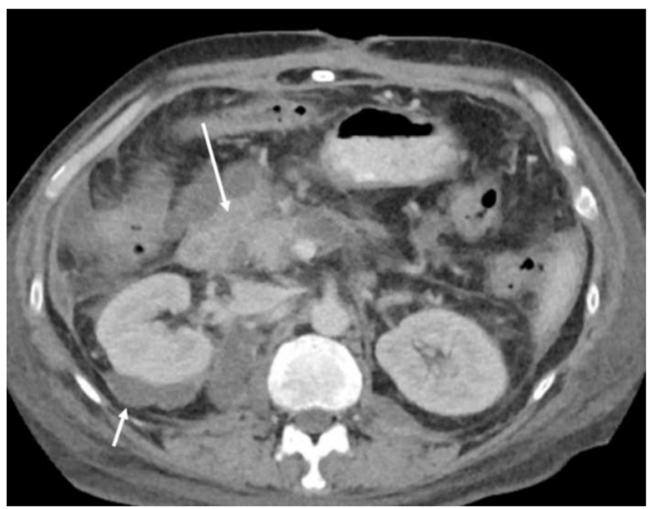

Fig. 10 A right perinephric pseudocyst (short arrow). Note the substantial inflammation in the anterior pararenal space centred on the pancreas (long arrow) in a patient with acute pancreatitis 


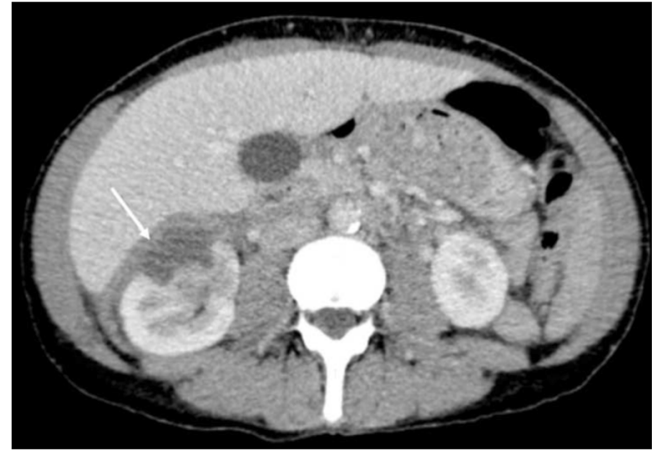

Fig. 11 Portal venous CT shows a right renal abscess that has burst into the perinephric space (arrow), best appreciated as the soft tissue density interposed between the kidney and adjacent liver

\section{Perinephric abscess}

Abscess within the perinephric space can present a diagnostic challenge. Depending on chronicity, aetiology and complications, it may mimic a tumour radiologically if chronic or may mandate evacuation and immediate treatment if acute. Predisposing factors for perinephric abscess include diabetes, pyelonephritis, urinary tract calculi and immunosuppression. Acute perinephric abscess is accompanied by fever, flank pain and leukocytosis. CT and MRI findings are non-specific and include thickening of the adjacent fascia, obliteration of

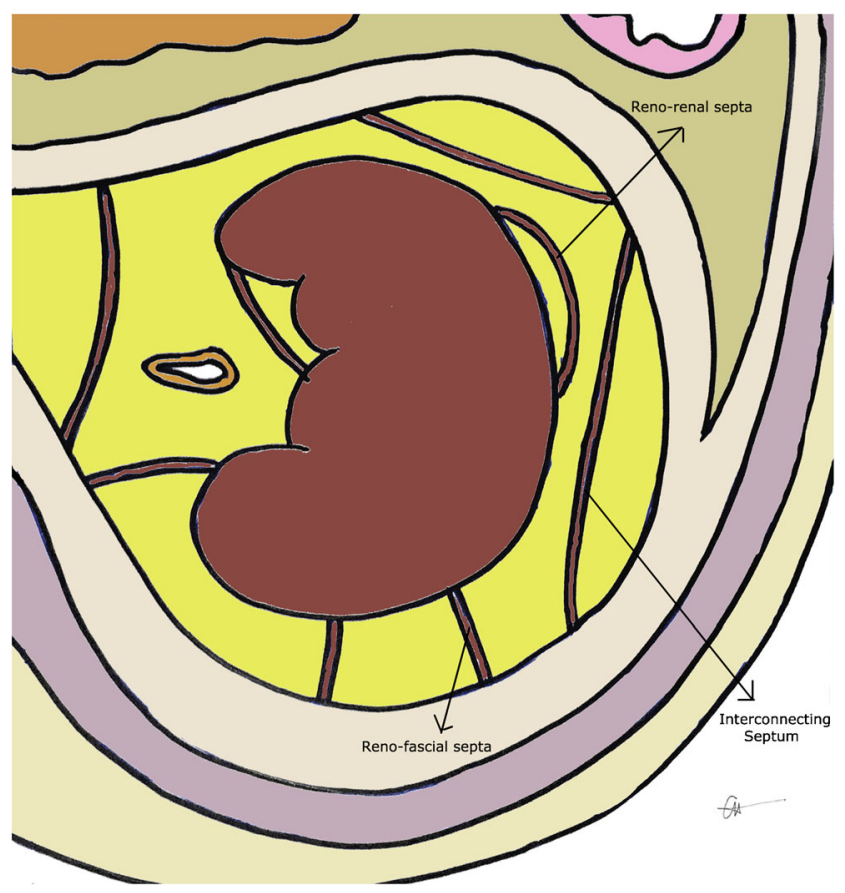

Fig. 12 Three types of bridging septa have been described: reno-renal, fibres running parallel to the renal capsule and attaching back onto the kidney; reno-fascial, septa connecting the capsule to the adjacent anterior or posterior renal fasciae; and interconnecting fascia, connecting the anterior and posterior layers of the perinephric fascia

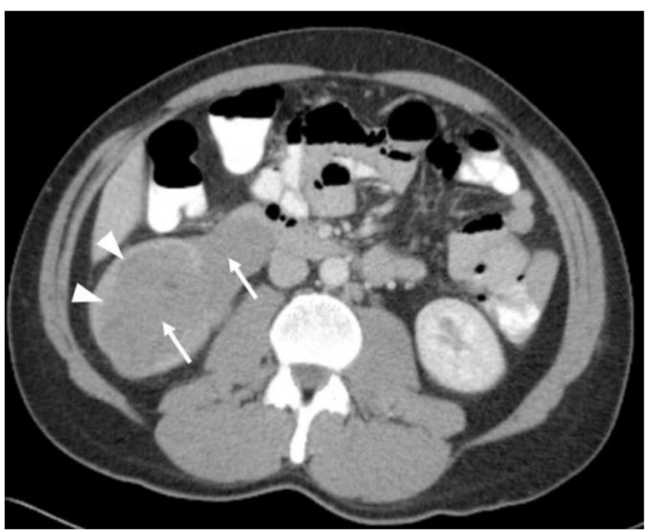

Fig. 13 Hypo-enhancing soft tissue fills the right renal pelvis, obliterating sinus fat and propagating along the proximal ureter (arrows). The overall reniform shape of the kidney is preserved, and the parenchyma is stretched but not invaded (arrowheads)

perinephric fat planes and fat stranding [29, 30]. Contrastenhanced CT imaging may demonstrate rim enhancement with central hypo-attenuation and thickened septa. The presence of thickened perinephric fascia and increased adjacent fat signalling are further suggestive of an infectious process rather than a malignant cystic neoplasm [3, 31] (Fig. 11).

In cases of emphysematous infection, CT can visualise gas extending from the kidney into the perinephric space. Xanthogranulomatous pyelonephritis, a rare progressively destructive process with lipid-rich macrophages replacing degenerative renal tissue, can also present with abscesses within the perinephric space as the inflammatory process spreads [3]. Imaging findings include unilateral enlargement of the kidney, heterogeneous parenchymal enhancement on contrastenhanced CT imaging, hydronephrosis and obstructive calculi [32].

\section{Thickened bridging septa}

Perinephric bridging septa (PBS) are composed of numerous fibrous lamellae which traverse the perinephric fat, extending from the renal capsule to the renal fascia and to other points on the posterolateral aspect of the capsule (Fig. 1). They serve to suspend the kidneys within the perirenal space [33]. Kunin [34] described three types of septa, as depicted in Fig. 12. PBS may serve as a conduit for the spread of inflammation, fluid or neoplasm from the kidney to the retromesenteric or retrorenal fascial planes, and can assist the radiologist in localising relevant pathology on abdominal imaging. Inflammation originating from the kidney may thicken the PBS and perinephric fascia. Urinary extravasation may thicken the PBS and appear as irregular perinephric or periureteral fluid collections. Fluid tracking along the PBS producing a liner or curvilinear pattern within the perinephric space is often seen in traumatic perinephric haematoma. 


\section{Retroperitoneal fibrosis}

Retroperitoneal fibrosis is characterised by the proliferation of fibro-inflammatory tissue, usually surrounding the infrarenal portion of the great vessels (aorta, inferior vena cava and iliac vessels) [35]. Perinephric fibrosis involving the ureters and kidney can result from extension of the infiltrative soft tissue process, causing hydronephrosis and hydroureter [36]. Imaging features of perinephric fibrosis exhibit a soft tissue infiltrate centred around the great vessels, with possible extension into the perinephric space and rarely into the retrorenal space and retromesenteric spaces [37]. CT imaging can depict fibro-inflammatory tissue with an attenuation coefficient similar to that of psoas muscle on non-contrast imaging, whilst contrast-enhanced CT imaging shows enhancement dependent on the stage of active disease. MRI shows low T1weighted signalling, with variable T2-weighted signalling, reflecting the degree of active inflammation (hypercellularity and oedema) [36]. The diagnosis of retroperitoneal fibrosis warrants biopsy and tissue sampling, as the disease although mostly idiopathic, can be secondary to a desmoplastic response to retroperitoneal metastases [38, 39].

\section{Neoplastic}

\section{Lymphoma}

Renal lymphoma is rarely seen as a primary renal lesion, with incidence of less than $1 \%$ [40]. Renal involvement tends to be secondary to systemic non-Hodgkin's lymphoma, especially B-cell lymphomas. Pathologic studies show that renal involvement is common. However, this is typically on a microscopic level, beyond the resolution of current imaging technology - hence a discord between autopsy rates of 30-60\% and imaging manifestations of 1-8\% [41-43]. Renal involvement can take the form of diffuse renal infiltration, solitary or

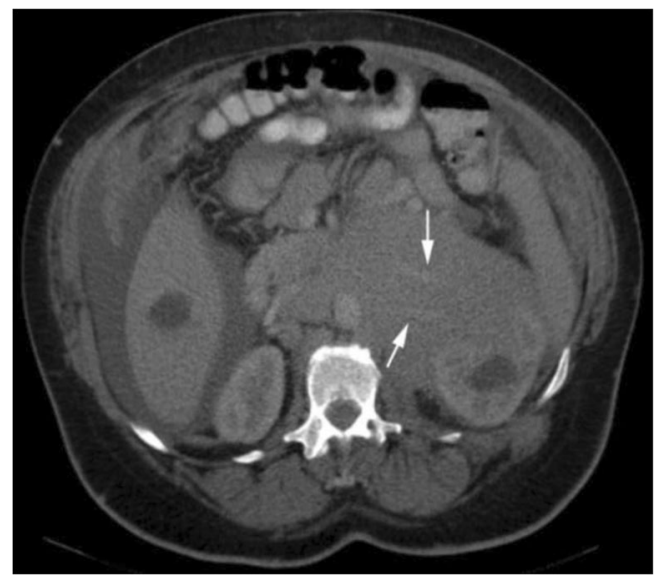

Fig. 14 Diffuse large B-cell lymphoma filling the left perirenal space and laterally displacing the kidney. The best clue to the diagnosis is that patent vessels can be seen passing through the mass (arrows)

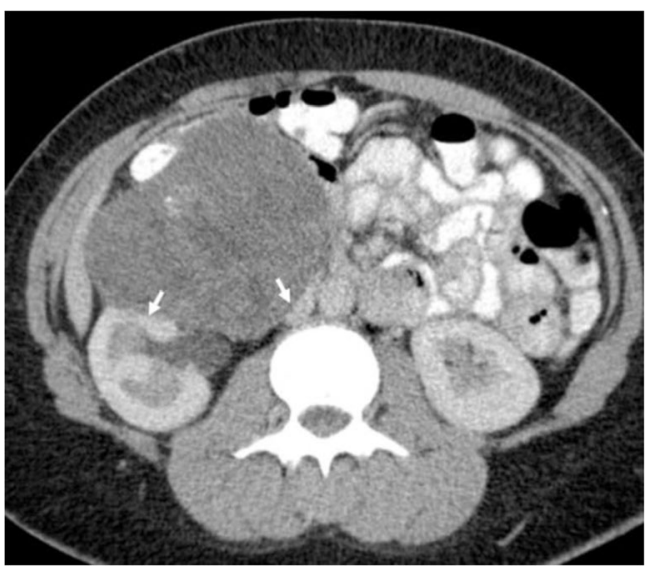

Fig. 15 A soft tissue mass indents the kidney and cava (short arrows) and displaces gut. Biopsy showed it was a liposarcoma, although no macroscopic fat was evident on imaging

multifocal masses, or soft tissue masses within the perinephric space. The perinephric involvement is due to contiguous spread from adjacent retroperitoneal lymph nodes or by extension along the ureter or from the adrenal [44]. The masses are homogenous, and in the absence of treatment, calcification and necrosis are rare. A key imaging feature suggesting the diagnosis is that despite often bulky disease that encases vessels and ureter, lymphoma usually does not produce obstruction (Fig. 13) or significant stenosis [45, 46]. Evidence of involvement at other sites such as the spleen or distant nodal stations should also alert the radiologist to the diagnosis.

At MRI, the masses have an intermediate signal on both T1- and T2-weighted images, although a high T2 signal may occur occasionally [41]. The enhancement may be more heterogeneous than that encountered on CT. The tumours have restricted diffusion, in keeping with small round blue-cell tumours encountered elsewhere.

It is usually seen as a spectrum of multi-system lymphoproliferative conditions. The genitourinary system is the second most commonly affected anatomic entity for extra-nodal

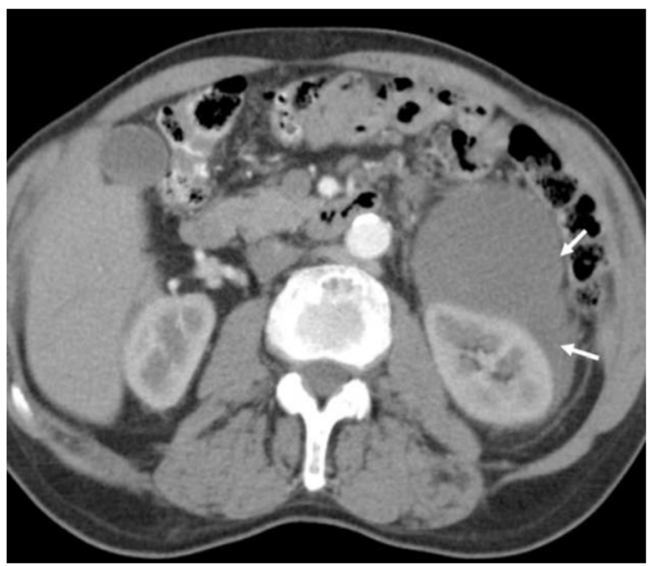

Fig. 16 A homogenous low-density myxosarcoma (arrows) in the left perirenal space encases the anterolateral kidney 


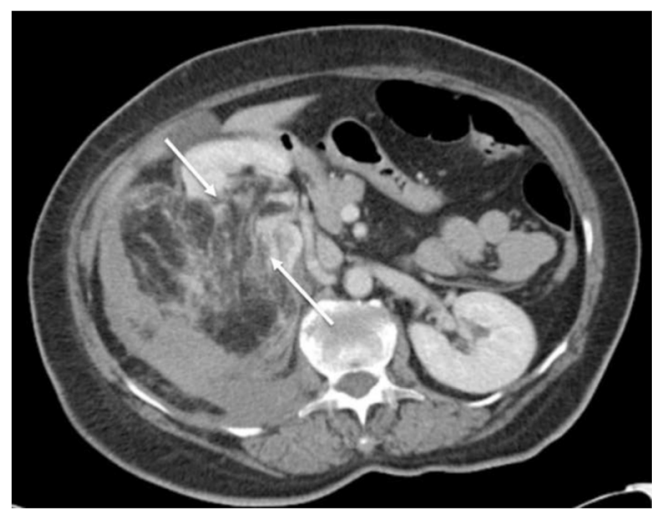

Fig. 17 Retroperitoneal blood in the perinephric space secondary to haemorrhage from a large angiomyolipoma, evident as a fatty cleft in the right kidney (arrows). Only a small amount of kidney can be seen on the medial side

spread of lymphoma, next to the haematopoietic and reticuloendothelial organs [45, 47]. CT remains the imaging modality of choice, but US, MRI and PET CT all have important diagnostic implications; combination PET/CT has shown staging sensitivity and specificity of up to $97 \%$ [48, 49]. The presentation of renal lymphoma can include single or multiple lesions, direct extension from retroperitoneal adenopathy, and diffuse infiltration of one or both kidneys [45]. Renal lymphoma enhances poorly on contrast-enhanced CT (Fig. 14).

\section{Liposarcoma}

Retroperitoneal sarcomas are rare tumours, and a number of subtypes may occur, the most common of which are liposarcoma and Leiomyosarcoma [50]. Due to the large potential space within the retroperitoneum, and late non-specific symptoms of retroperitoneal sarcomas, they are frequently large at the time of diagnosis. As such, retroperitoneal space involvement carries a poor prognosis, as does tumour grade $[51,52]$. This has led to more aggressive surgical resection and radiation therapy, thus requiring an accurate description of the anatomical boundaries of the tumour to guide therapy.

Liposarcoma remains the most common primary retroperitoneal malignancy and the second most common presentation of soft tissue sarcoma after pleomorphic undifferentiated sarcoma [53, 54]. Four subtypes are described: well-differentiated or atypical lipomatous tumour (most common subtype), myxoid including round cell, de-differentiated (least common subtype) and pleomorphic [55]. Imaging findings commonly reflect underlying histological subtype [56, 57]. Lesions that are primarily composed of macroscopic fat tend to be well-differentiated, demonstrating fat attenuation on CT and following fat signal on MRI, with a paucity of soft tissue elements. It is important when performing biopsy to target the soft tissue component of the tumour, as these are frequently

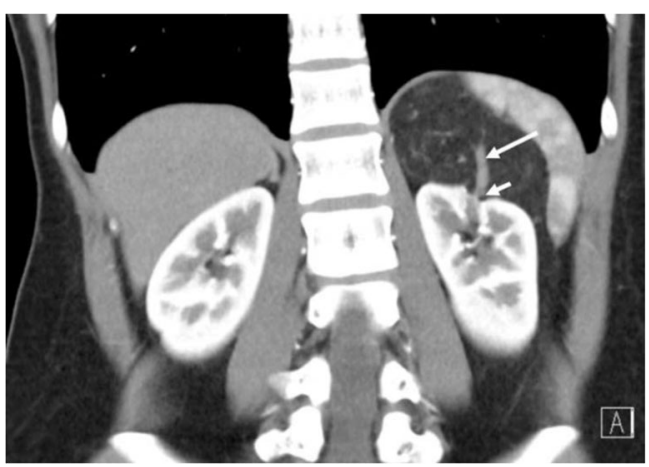

Fig. 18 A predominantly fat-containing exophytic suprarenal angiomyolipoma. Note the small cleft (short arrow) in the superior pole renal cortex and the prominent vessel (long arrow) passing through this

the poorly differentiated component [53]. Macroscopically, these tumours show greater than $75 \%$ fat composition [58]. De-differentiated tumours will share radiological characteristics with well-differentiated liposarcoma and will have additional focal, nodular non-lipomatous regions greater than $1 \mathrm{~cm}$ in size [59]. Calcification or ossification within a liposarcoma has been shown to be a poor prognostic feature [50]. Pleomorphic liposarcomas tend to appear more as soft tissue masses without defining lipomatous characteristics (Fig. 15) and with extensive anaplasia [53]. Myxoid liposarcomas (Fig. 16) can appear cystic and can have elevated T2 signal intensity in non-lipomatous elements, with a tendency for reticular enhancement [60]. Ultrasound can be useful in myxoid subtypes, as sonography can demonstrate that the mass is not truly cystic, and further investigation with biopsy may be warranted.

In well-differentiated primarily fatty masses, it is important to search for a defect within the renal capsule, as when a lesion is present, it most likely represents an angiomyolipoma rather than a sarcoma [61]. The adrenal gland should also be inspected to differentiate the mass from an adrenal myelolipoma.

\section{Leiomyosarcoma}

Leiomyosarcoma is the second most common primary retroperitoneal malignancy in adults [54]. These tumours can be intravascular $(62 \%)$, extravascular $(5 \%)$ or a combination of both $(33 \%)$ [46]. The tumour origin comprises cells showing distinct smooth muscle features, and retroperitoneal malignancy is believed to originate from vessels, smooth muscle of the renal capsule, renal pelvis, calyxes and embryological remnants within the retroperitoneum [62]. Diagnosis is often late, given the nonspecific clinical findings and the relative accommodation of tumour growth provided by the retroperitoneum. $\mathrm{CT}$ and MR imaging tend to demonstrate heterogeneous large tumours with extensive necrotic and cystic change [46]. 


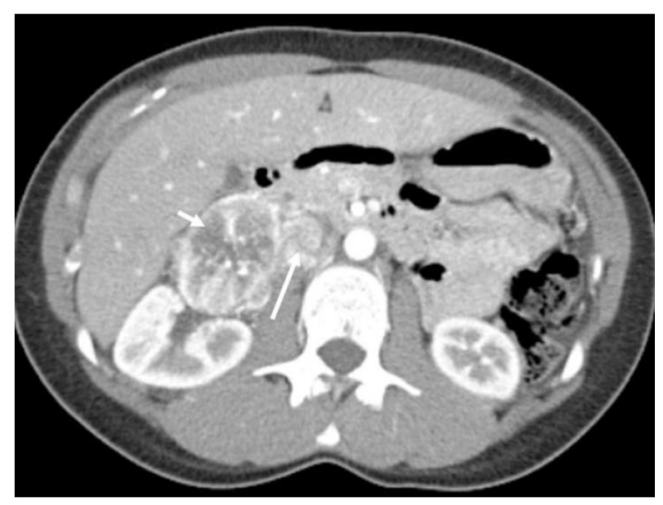

Fig. 19 Axial portal venous CT shows a heterogeneous mass (short arrow) at the right renal hilum, with invasion of the inferior vena cava (long arrow). This was excised and was pathologically shown to be a phaeochromocytoma

\section{Angiomyolipoma}

Angiomyolipoma (AML) is a mesenchymal neoplasm composed of blood vessels, smooth muscle and adipose tissue [57]. AML occur sporadically in $80 \%$ of cases with a prevalence of $0.2 \%-0.4 \%$ or as part of an autosomal dominant condition known as tuberous sclerosis complex (TSC) and have a female predilection $[63,64]$. AML's are observed in 55\%$75 \%$ of patients with TSC and present earlier in life [65]. Renal AMLs with perinephric extension are the most common macroscopic fat-containing mass in the perirenal region [66]. They are often incidental when imaging the retroperitoneal space, but do have a propensity to bleed (Fig. 17) when lesions grow larger than $4 \mathrm{~cm}$ or intratumoral aneurysmal change exceeds $5 \mathrm{~mm}[7,67]$. Imaging modalities are aimed at demonstrating fat within the suspected lesion, although in settings of AML and associated tuberous sclerosis, up to a third of all AMLs will be fat-poor [68]. As AML originates primarily from the renal parenchyma, it can be easily distinguished from a liposarcoma by a "beak sign" or divot at the interface of the kidney and mass, often with a perforating feeding vessel [69, 70] (Fig. 18). Calcifications are further more suggestive of liposarcoma over AML [71].

\section{Neoplastic}

\section{Solitary fibrous tumour}

Solitary fibrous tumour (SFT) of the kidney is a rare entity. Initially believed to be solely a pleural malignancy, referred to as "benign fibrous mesothelioma", SFTs can be seen anywhere throughout the body [72, 73]. Most SFTs are benign and appear as slow-growing masses in middle-aged adults, with equal frequency in men and women [74, 75]. Surgical excision is the treatment of choice, with 5-year survival close to $90 \%$ with complete excision [76]; however, complete

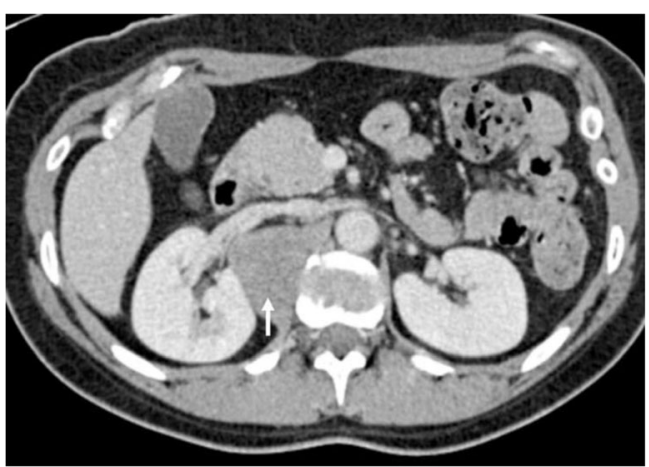

Fig. 20 A homogenous low-density mass extending into the right perinephric space (arrow), with broad contact with the psoas fascia. This is a biopsy-proven neurofibroma

clearance is required, as up to $20 \%$ of SFTs can exhibit malignant potential $[76,77]$. SFTs on imaging display hypervascular signalling on contrast-enhanced CT. T1weighted MR shows intermediate signalling, with flow voids on T2-weighted imaging due to dense collagen and fibrosis [53]. Intense enhancement is seen after administration of gadolinium contrast material [78].

\section{Desmoid tumour}

Desmoid tumours or aggressive fibromatosis develop from musculoaponeurotic tissue and can be sporadic or familial, such as familial adenomatous polyposis (FAP) or Gardner syndrome [46]. Desmoid tumours are hormonally responsive to oestrogen, and as such are more common in women from puberty to 40 years of age [56, 57]. Tumours usually are less than $10 \mathrm{~cm}$ in diameter and are defined as intermediate/locally aggressive. Malignant transformation is rare [79, 80]. Histologically, desmoid tumours vary based on tissue composition (spindle cells, collagen, myxoid matrix). Imaging characteristics differ depending on the composition within the tumour, and vascularity may change with time, leading to evolving CT and MR dynamic imaging features [81]. Contrast enhancement is seen for most desmoid tumours, and heterogeneous signalling is common [82, 83]. An infiltrative border in the form of a fascial tail may be seen in up to $80 \%$ of cases on MRI [81]. T2-weighted MRI may demonstrate hypointense bands within the tumour that correlate with dense collagenous bands seen on histology [82].

\section{Phaeochromocytoma}

Phaeochromocytomas (PCCs) and abdominal paragangliomas are rare catecholamine-producing tumours. Incidence patterns show that men and women are affected equally, in the fourth to fifth decades of life [84]. Most (90\%) PCCs are located in the adrenal gland [85]. They can occur both as sporadic 


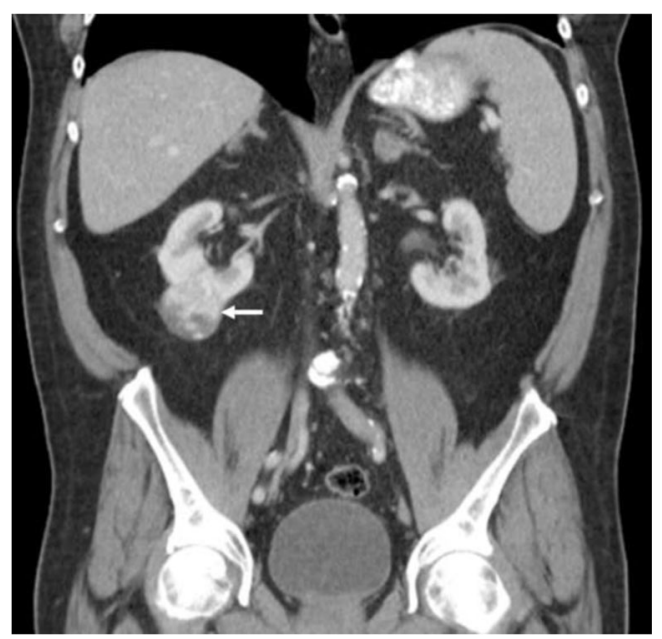

Fig. 21 Coronal portal venous CT demonstrating an exophytic heterogeneous renal cell carcinoma arising from the lower pole of the right kidney (arrow)

tumours and as a manifestation of genetic disease [86]. MRI remains the morphological imaging modality of choice in localising PCC and extra-adrenal paragangliomas, offering better contrast resolution than $\mathrm{CT}$ and without ionising radiation [87]. PCCs appear hypointense or iso-intense on T1weighted imaging and markedly hyperintense on T2weighted images. CT imaging will show a soft tissue density that enhances markedly with contrast administration, often showing areas of calcification or central necrosis [88, 89] (Fig. 19). When morphological imaging and biochemical investigations of lesions are indeterminate, functional imaging utilising meta-iodobenzylguanide $\left({ }^{123} \mathrm{I}-\mathrm{MIBG}\right)$ can achieve specificity of up to $99 \%$ and sensitivity of $77-90 \%$ in the diagnosis of PCC, and remains the most important nuclear imagining tool currently in service [89]. It is important to consider paraganglioma in appropriate cases, especially if biopsy is planned, as biopsy may lead to a catecholamine crisis characterised by headache, hypertension, sweating, haemodynamic compromise and even death. Positron emission tomography has emerged as an important diagnostic tool in adrenal malignancies due to its functional and concurrent anatomical localisation in combined PET/high-resolution CT. $\left[{ }^{18} \mathrm{~F}\right]$ fluorodeoxy-D-glucose (FDG) when taken in by metabolically active adrenal malignancies, can localise and correlate with structural anatomy yet currently lacks the specificity required as an initial investigation of choice [87]. ${ }^{18} \mathrm{~F}-\mathrm{FDOPA}$ (6-[18F]-L-fluoro-L-3,4-dihydroxyphenylalanine)-based PET/CT has shown sensitivity profiles close to $95 \%$ in diagnosing PCCs and abdominal paragangliomas, reaching $100 \%$ concordance with MRI for the detection of PCCs [90].

\section{Neurofibroma}

Neurofibroma is a benign nerve sheath tumour more often seen as an isolated entity $(90 \%)$ rather than in conjunction with associated genetic conditions such as neurofibromatosis. They consist of Schwann cells, fibroblasts and rich networks of collagen fibres. More common in men, its incidence occurs in young to middle-aged men, 20 to 40 years of age [91]. On CT imaging, neurofibroma are homogenous (Fig. 20), smooth and round with distinct outlines. Imaging characteristics are secondary to their lipid rich architecture and collagen deposits [91, 92]. MRI shows hypointense T1-weighted imaging consistent with neural tissue. In addition, high peripheral signalling on T2-weighted images with low central signalling can be seen due to myxoid degeneration peripherally and nerve tissue centrally [93]. When multiple neurofibroma are present, neurofibromatosis should be considered. Unlike schwannoma,

Table 2 Renal cell histological subtypes

\begin{tabular}{|c|c|c|c|c|c|c|c|}
\hline Subtype & Incidence & Origin & $\begin{array}{l}\text { Patient } \\
\text { age }\end{array}$ & Signal density & $\begin{array}{l}\text { Biological } \\
\text { behaviour }\end{array}$ & $\begin{array}{l}\text { Post- } \\
\text { contrast }\end{array}$ & Associations \\
\hline Clear cell & $75 \%$ & $\begin{array}{l}\text { Proximal nephron, } \\
\text { tubular epithelium }\end{array}$ & $\begin{array}{l}>50 \\
\text { years }\end{array}$ & $\begin{array}{l}\text { Heterogeneous } \\
\text { density/signal }\end{array}$ & Aggressive & Hypervascular & $\begin{array}{l}\text { Von Hippel- } \\
\text { Lindau (25-45\%), } \\
\text { tuberous sclerosis } \\
(2 \%)\end{array}$ \\
\hline Papillary & $10 \%$ & $\begin{array}{l}\text { Distal nephron, } \\
\text { tubular epithelium }\end{array}$ & $\begin{array}{l}>50 \\
\text { years }\end{array}$ & $\begin{array}{l}\text { Low T2 signal, } \\
\text { hypodense }\end{array}$ & Aggressive & Hypovascular & $\begin{array}{l}\text { Hereditary } \\
\text { papillary RCC }\end{array}$ \\
\hline Chromophobe & $5 \%$ & Distal nephron & $\begin{array}{l}>50 \\
\quad \text { years }\end{array}$ & $\begin{array}{l}\text { Hypodense, } \\
\text { intermediate } \\
\text { signal density }\end{array}$ & $\begin{array}{l}\text { Low mortality } \\
\qquad(10 \%)\end{array}$ & Hypovascular & $\begin{array}{l}\text { Birt-Hogg-Dubé } \\
\text { syndrome }\end{array}$ \\
\hline $\begin{array}{l}\text { Collecting duct } \\
\text { carcinoma }\end{array}$ & $\sim 1 \%$ & $\begin{array}{l}\text { Medullary } \\
\text { collecting duct }\end{array}$ & $\begin{array}{l}>50 \\
\quad \text { years }\end{array}$ & $\begin{array}{l}\text { Heterogeneous } \\
\text { density, low } \\
\text { T2 signal }\end{array}$ & $\begin{array}{l}\text { Highly } \\
\text { aggressive }\end{array}$ & Hypovascular & \\
\hline Medullary & $\sim 1 \%$ & Distal nephron & $\begin{array}{l}20-40 \\
\text { years }\end{array}$ & $\begin{array}{l}\text { Heterogeneous, } \\
\text { infiltrative, } \\
\text { low T2 signal }\end{array}$ & $\begin{array}{l}\text { Extremely } \\
\text { aggressive }\end{array}$ & Hypovascular & $\begin{array}{c}\text { Sickle cell } \\
\text { disease }\end{array}$ \\
\hline
\end{tabular}




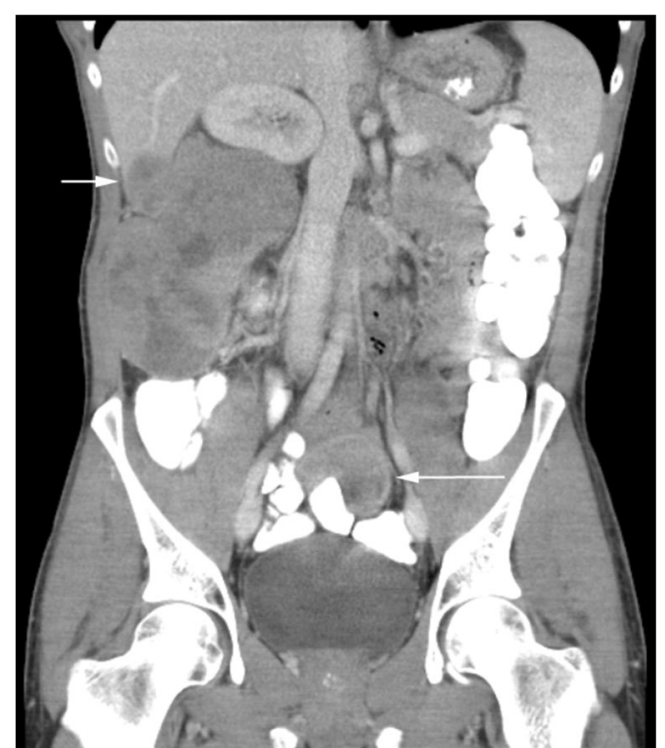

Fig. 22 A large perinephric heterogeneous melanoma metastatic mass displaces the right kidney superiorly. A separate liver metastasis is present (short arrow), as is a metastasis to the small bowel (long arrow)

neurofibroma are inseparable from the normal nerve, and surgical excision must include the adjacent nerve [94].

\section{Renal cell carcinoma}

Renal cell carcinoma (RCC) remains the most common presentation of malignancy arising from the kidney, accounting for $2-3 \%$ of all adult malignancies, with a median age at diagnosis of 65 years and a significant male predilection [95, 96]. The diagnosis of renal cell cancer encompasses a multitude of distinct cytogenetic and immunohistochemical properties that carry with them differing prognoses and imaging characteristics [97]. Clear cell subtypes remain the most frequent in presentation $(75 \%)$, followed by papillary (10\%) and the rarer chromophobe (5\%), collecting duct and medullary

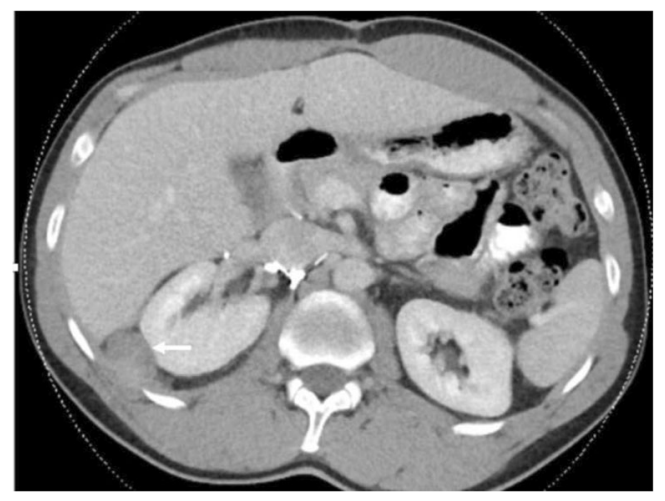

Fig. 23 Axial portal venous phase CT shows a homogenous soft tissue metastasis in the right perinephric space, slightly indenting the adjacent kidney (arrow). The primary tumour, an adrenal carcinoma, had been excised previously (see clips dorsal to the inferior vena cava)
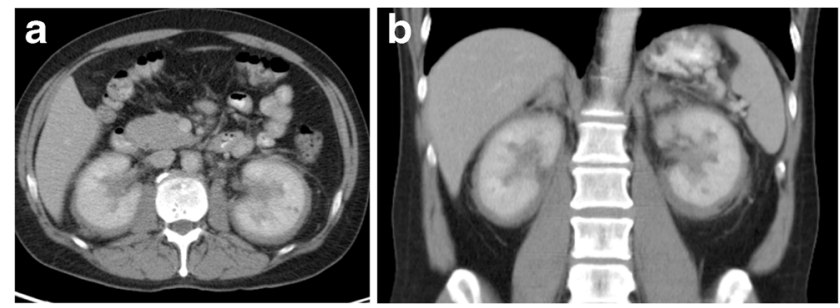

Fig. 24 a A portal venous phase CT shows a soft tissue rind encasing both kidneys and extending into the renal sinus. b The coronal reconstruction shows underlying renal parenchyma appearing normal in this patient with Erdheim-Chester disease

subtypes [98]. Recent literature has suggested racial differences in the distribution of histological subtype [99]. The gross morphological profile of RCC can further delineate subtype, with clear cell RCC typically exhibiting exophytic growth patterns. This pattern is important as a differential for visualised masses in the perinephric space (Fig. 21). RCC that extends or spreads into the perinephric space is considered a T3 tumour and carries significant prognostic implications [100]. Other features that may differentiate histological subtype on imaging include intralesional heterogeneity, fat and enhancement patterns with contrast agents $[101,102]$. The different imaging characteristics of the common histological subtypes of renal cell cancer are described in Table 2 [97, 98, 103]. Focal solid masses in the perinephric space are most commonly due to malignancy, and differential considerations include tumour extension from renal, adrenal or retroperitoneal sources [29].

\section{Extra-gastrointestinal stromal tumour}

Primary extra-gastrointestinal stromal tumour (EGIST) in perirenal locations is extremely rare. Gastrointestinal stromal

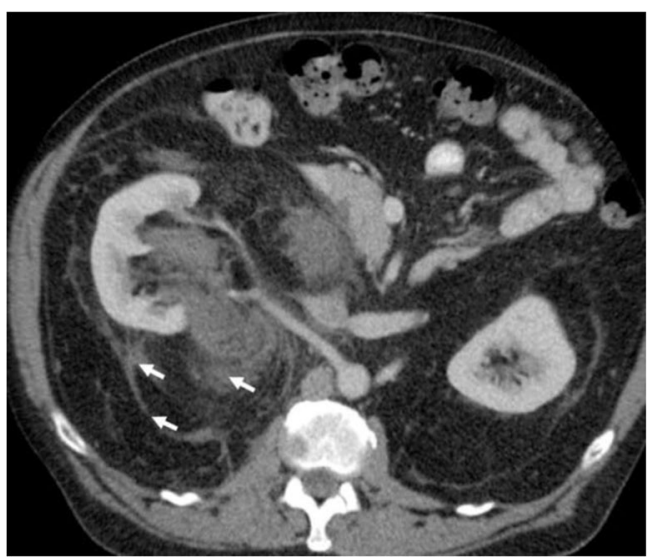

Fig. 25 Marked expansion of the right perinephric fat with irregular soft tissue bands passing through it (arrows). More nodular soft tissue is present in the sinus fat and medial aspect of the perinephric space in this patient with excision-proven Rosai-Dorfman disease 
tumour (GIST) is a non-epithelial neoplasm arising from the muscularis propria layer (interstitial cells of Cajal) of the GI tract, with characteristic exophytic growth patterns [104, 105]. Among the presentations of extra-gastrointestinal stromal tumours, most are found in the omentum and mesentery [104]. Perirenal EGISTs appear as hypovascular soft tissue masses, often non-specific, and diagnosis relies heavily on biopsy and histological analyses rather than imaging interpretation. MRI shows varying degrees of heterogeneity and signalling on both T1- and T2-weighted images, with T1-weighted imaging showing low signal intensity (iso-intense to skeletal muscle) and multiple markedly hypointense linear bands [106].

\section{Metastases}

The perinephric space is an unusual site for secondary spread of malignancy. Imaging findings vary depending on the type of primary tumour. Most perinephric metastases present as multiple discrete soft tissue masses (Fig. 22). Pulmonary malignancies show a predilection for the perinephric space secondary to connections between the perirenal and mediastinal lymphatic vessels [107]. Primary metastases from melanoma, prostate, breast and gastrointestinal tumours spread via haematogenous routes, whilst pulmonary malignancies may track into the perinephric space via lymphatic spread. Metastatic spread from solid organs directly into the perinephric space can occur (Fig. 23), and local adjacent structures should be assessed for primary malignancy [29].

\section{Proliferative}

\section{Erdheim-Chester disease}

Erdheim-Chester disease (lipoid granulomatosis) is a systemic non-Langerhans cell histiocytosis of unknown aetiology [108]. It affects middle-aged individuals, with no sex predilection. Perirenal involvement characteristically shows a rindlike soft tissue mass enveloping the kidney and proximal ureter (Fig. 24). MR shows low signal on both T1- and T2weighted imaging, with minimal contrast enhancement. Progressive renal failure can occur secondary to fibrous perinephritis [108]. Treatment involves retrograde ureteral catheterisation and corticosteroid/immunosuppressive therapy until active inflammation resolves. Long bone abnormalities are crucial findings for recognition of this disease; findings, often bilateral, include cortical and medullary sclerosis and metadiaphyseal cortical thickening with sparing of the epiphyses $[108,109]$. MRI can also be useful in evaluating the extent of medullary bone disease and confirming the presence of osteonecrosis [110].

\section{Rosai-Dorfman disease}

Rosai-Dorfman disease (sinus histiocytosis with massive lymphadenopathy) is a proliferative benign disorder characterised by proliferation of histiocytes, with clinical features suggestive of lymphoma-like disease. The disease process tends to affect children and young adults, with extranodal disease present in approximately $40 \%$ [111]. Common extra-nodal sites involve the skin, head and neck, and bone. Renal involvement is rare and is seen in $4 \%$ of extra-nodal disease. CT imaging can visualise unusual hilar masses or subcapsular infiltration with varying degrees of enhancement $[112,113]$. Rosai-Dorfman has been characterised by heterogeneous masses containing low-density elements almost approaching fat, with marked expansion of the perinephric space (Fig. 25); the kidneys may also be displaced and may show evidence of subcapsular infiltration [114].

Open Access This article is distributed under the terms of the Creative Commons Attribution 4.0 International License (http:// creativecommons.org/licenses/by/4.0/), which permits unrestricted use, distribution, and reproduction in any medium, provided you give appropriate credit to the original author(s) and the source, provide a link to the Creative Commons license, and indicate if changes were made.

\section{References}

1. Tirkes T, Sandrasegaran K, Patel AA et al (2012) Peritoneal and retroperitoneal anatomy and its relevance for cross-sectional imaging. RadioGraphics 32:437-451

2. Aizenstein RI, Wilbur AC, O’Neil HK (1997) Interfascial and perinephric pathways in the spread of retroperitoneal disease: refined concepts based on CT observations. AJR Am J Roentgenol 168:639-643

3. Heller MT, Haarer KA, Thomas E, Thaete F (2012) Acute conditions affecting the perinephric space: imaging anatomy, pathways of disease spread, and differential diagnosis. Emerg Radiol 19: 245-254

4. Skandalakis LJ (2004) Skandalakis' surgical anatomy: the embryologic and anatomic basis of modern surgery. McGrawHill, Athens, Greece

5. Lai S-L, Spanger M (2012) Role of computed tomography in perirenal haematoma; a pictorial review. Internet J Radiol 14:1-9

6. Adam A, Dixon AK, Gillard J, Schaefer-Prokop C, Grainger RG, Allison DJ (2014) Grainger \& allison's diagnostic radiology. Churchill Livingstone, p 993-1001

7. Chen L-K, Chen Y-H, Lin Y-M, Chang C-C, Lo W-Y, Lee C-C (2007) Imaging diagnosis of renal angiomyolipoma on computed tomography. Chin J Radiol 32:167-176

8. Zhang JQ, Fielding JR, Zou KH (2002) Etiology of spontaneous perirenal hemorrhage: a meta-analysis. J Urol 167:1593-1596

9. Haddad MC, Hawary MM, Khoury NJ, Abi-Fakher FS, Ammouri NF, Al-Kutoubi AO (2002) Radiology of perinephric fluid collections. Clin Radiol 57:339-346

10. Belville JS, Morgentaler A, Loughlin KR, Tumeh SS (1989) Spontaneous perinephric and subcapsular renal hemorrhage: evaluation with CT, US, and angiography. Radiology 172:733-738 
11. Diaz JR, Agriantonis DJ, Aguila J, Calleros JE, Ayyappan AP (2011) Spontaneous perirenal hemorrhage: what radiologists need to know. Emerg Radiol 18:329-334

12. Titton RL, Gervais DA, Hahn PF, Harisinghani MG, Arellano RS, Mueller PR (2003) Urine leaks and urinomas: diagnosis and imaging-guided intervention. RadioGraphics 23:1133-1147

13. Gayer G, Zissin R, Apter S et al (2002) Urinomas caused by ureteral injuries: CT appearance. Abdom Imaging 27:88-92

14. Levy AD, Cantisani V, Miettinen M (2004) Abdominal lymphangiomas: imaging features with pathologic correlation. Am J Roentgenol 182:1485-1491

15. Lugo-Olivieri CH, Taylor GA (1993) CT differentiation of large abdominal lymphangioma from ascites. Pediatr Radiol 23:129 130

16. Romeo V, Maurea S, Mainenti PP et al (2015) Correlative imaging of cystic lymphangiomas: ultrasound, CT and MRI comparison. Acta Radiol Open 4:2047981614564911

17. Ramseyer LT (2001) Case 34: renal lymphangiectasia. Radiology 219:442-444

18. Honma I, Takagi Y, Shigyo M et al (2002) Lymphangioma of the kidney. Int J Urol 9:178-182

19. Elbanna KY, Almutairi BM, Zidan AT (2015) Bilateral renal lymphangiectasia: radiological findings by ultrasound, computed tomography, and magnetic resonance imaging. J Clin Imaging Sci $5: 6$

20. Karkouche R, Rocher L, Guettier C et al (2013) Bilateral renal lymphangiomatosis: imaging and histopathologic findings. Abdom Imaging 38:858-862

21. Cui ML, Kim KH, Kim HG et al (2014) Incidence, risk factors and clinical course of pancreatic fluid collections in acute pancreatitis. Dig Dis Sci 59:1055-1062

22. Lankisch PG, Weber-Dany B, Maisonneuve P, Lowenfels AB (2012) Pancreatic pseudocysts: prognostic factors for their development and their spontaneous resolution in the setting of acute pancreatitis. Pancreatology 12:85-90

23. Banks PA, Bollen TL, Dervenis C et al (2013) Classification of acute pancreatitis - 2012: revision of the Atlanta classification and definitions by international consensus. Gut 62:102-111

24. London NJ, Neoptolemos JP, Lavelle J, Bailey I, James D (1989) Serial computed tomography scanning in acute pancreatitis: a prospective study. Gut 30:397-403

25. Habashi S, Draganov PV (2009) Pancreatic pseudocyst. World J Gastroenterol: WJG 15:38-47

26. Aghdassi AA, Mayerle J, Kraft M, Sielenkämper AW, Heidecke C-D, Lerch MM (2006) Pancreatic pseudocysts - when and how to treat? HPB: Off J In Hepato Pancreato Biliary Assoc 8:432-441

27. Varghese JC, Masterson A, Lee MJ (2002) Value of MR pancreatography in the evaluation of patients with chronic pancreatitis. Clin Radiol 57:393-401

28. Xiao B, Zhang X-M, Tang W, Zeng N-L, Zhai Z-H (2010) Magnetic resonance imaging for local complications of acute pancreatitis: A pictorial review. World J Gastroenterol: WJG 16: 2735-2742

29. Heller MT, Haarer KA, Thomas E, Thaete FL (2012) Neoplastic and proliferative disorders of the perinephric space. Clin Radiol 67:e31-41

30. Stunell H, Buckley O, Feeney J, Geoghegan T, Browne RF, Torreggiani WC (2007) Imaging of acute pyelonephritis in the adult. Eur Radiol 17:1820-1828

31. Demertzis J, Menias CO (2007) State of the art: imaging of renal infections. Emerg Radiol 14:13-22

32. Loffroy R, Guiu B, Watfa J, Michel F, Cercueil JP, Krause D (2007) Xanthogranulomatous pyelonephritis in adults: clinical and radiological findings in diffuse and focal forms. Clin Radiol 62:884-890
33. Bechtold RE, Dyer RB, Zagoria RJ, Chen MY (1996) The perirenal space: relationship of pathologic processes to normal retroperitoneal anatomy. RadioGraphics 16:841-854

34. Kunin M (1986) Bridging septa of the perinephric space: anatomic, pathologic, and diagnostic considerations. Radiology 158:361365

35. Cronin CG, Lohan DG, Blake MA, Roche C, McCarthy P, Murphy JM (2008) Retroperitoneal fibrosis: a review of clinical features and imaging findings. Am J Roentgenol 191:423-431

36. Caiafa RO, Vinuesa AS, Izquierdo RS, Brufau BP, Colella JRA, Molina CN (2013) Retroperitoneal fibrosis: role of imaging in diagnosis and follow-up. RadioGraphics 33:535-552

37. Urban ML, Palmisano A, Nicastro M, Corradi D, Buzio C, Vaglio A (2015) Idiopathic and secondary forms of retroperitoneal fibrosis: a diagnostic approach. Rev Med Interne 36:15-21

38. Vaglio A, Salvarani C, Buzio C (2006) Retroperitoneal fibrosis. Lancet 367:241-251

39. Kottra JJ, Dunnick NR (1996) Retroperitoneal fibrosis. Radiol Clin North Am 34:1259-1275

40. Hagihara M, Hua J, Iwaki Y, Inoue M, Sato T (2015) Primary renal lymphoma: a case report and literature review. Intern Med 54:2655-2659

41. Ganeshan D, Iyer R, Devine C, Bhosale P, Paulson E (2013) Imaging of primary and secondary renal lymphoma. Am J Roentgenol 201:W712-W719

42. Reznek RH, Mootoosamy I, Webb JA, Richards MA (1990) CT in renal and perirenal lymphoma: a further look. Clin Radiol 42:233238

43. Urban BA, Fishman EK (2000) Renal lymphoma: CT patterns with emphasis on helical CT. RadioGraphics 20:197-212

44. El-Sharkawy MS, Siddiqui N, Aleem A, Diab AA (2007) Renal involvement in lymphoma: prevalence and various patterns of involvement on abdominal CT. Int Urol Nephrol 39:929-933

45. Sheth S, Ali S, Fishman E (2006) Imaging of renal lymphoma: patterns of disease with pathologic correlation. RadioGraphics 26: 1151-1168

46. Rajiah P, Sinha R, Cuevas C, Dubinsky TJ, Bush WH Jr, Kolokythas O (2011) Imaging of uncommon retroperitoneal masses. RadioGraphics 31:949-976

47. Richmond J, Sherman RS, Diamond HD, Craver LF (1962) Renal lesions associated with malignant lymphomas. Am J Med 32:184 207

48. Kwee TC, Kwee RM, Nievelstein RA (2008) Imaging in staging of malignant lymphoma: a systematic review. Blood 111:504-516

49. Paes FM, Kalkanis DG, Sideras PA, Serafini AN (2010) FDG $\mathrm{PET} / \mathrm{CT}$ of extranodal involvement in non-Hodgkin lymphoma and Hodgkin disease. RadioGraphics 30:269-291

50. Francis IR, Cohan RH, Varma DGK, Sondak VK (2005) Retroperitoneal sarcomas. Cancer Imaging 5:89-94

51. Gronchi A, Lo Vullo S, Fiore M et al (2009) Aggressive surgical policies in a retrospectively reviewed single-institution case series of retroperitoneal soft tissue sarcoma patients. J Clin Oncol 27:24 30

52. Linehan DC, Lewis JJ, Leung D, Brennan MF (2000) Influence of biologic factors and anatomic site in completely resected liposarcoma. J Clin Oncol 18:1637-1643

53. Brennan C, Kajal D, Khalili K, Ghai S (2014) Solid malignant retroperitoneal masses - a pictorial review. Insights Imaging 5: 53-65

54. Neville A, Herts BR (2004) CT characteristics of primary retroperitoneal neoplasms. Crit Rev Comput Tomogr 45:247-270

55. Fletcher CDM, Unni KK, Mertens F (2013) World Health Organization Classification of Tumours; Pathology and Genetics. Tumours of Soft Tissue and Bone. IARC Press 
56. Kransdorf MJ (1995) Malignant soft-tissue tumors in a large referral population: distribution of diagnoses by age, sex, and location. AJR Am J Roentgenol 164:129-134

57. Craig WD, Fanburg-Smith JC, Henry LR, Guerrero R, Barton JH (2009) Fatcontaining lesions of the retroperitoneum: radiologicpathologic correlation. RadioGraphics 29:261-290

58. Song T, Shen J, Liang BL, Mai WW, Li Y, Guo HC (2007) Retroperitoneal liposarcoma: MR characteristics and pathological correlative analysis. Abdom Imaging 32:668-674

59. Murphey MD, Arcara LK, Fanburg-Smith J (2005) Imaging of musculoskeletal liposarcoma with radiologic-pathologic correlation. RadioGraphics 25:1371-1395

60. Walker EA, Song AJ, Murphey MD (2010) Magnetic resonance imaging of softtissue masses. Semin Roentgenol 45:277-297

61. Le O, Roy A, Silverman PM, Kundra V (2012) Common and uncommon adult unilateral renal masses other than renal cell carcinoma. Cancer Imaging 12:194-204

62. Ozturk H (2015) High-grade primary renal leiomyosarcoma. Int Braz J Urol 41:304-311

63. Fittschen A, Wendlik I, Oeztuerk S et al (2014) Prevalence of sporadic renal angiomyolipoma: a retrospective analysis of 61 , 389 in- and out-patients. Abdom Imaging 39:1009-1013

64. Fujii Y, Ajima J, Oka K, Tosaka A, Takehara Y (1995) Benign renal tumors detected among healthy adults by abdominal ultrasonography. Eur Urol 27:124-127

65. Crino PB, Nathanson KL, Henske EP (2006) The tuberous sclerosis complex. N Engl J Med 355:1345-1356

66. Surabhi VR, Menias C, Prasad SR, Patel AH, Nagar A, Dalrymple NC (2008) Neoplastic and non-neoplastic proliferative disorders of the perirenal space: crosssectional imaging findings. RadioGraphics 28:1005-1017

67. Yamakado K, Tanaka N, Nakagawa T, Kobayashi S, Yanagawa M, Takeda K (2002) Renal angiomyolipoma: relationships between tumor size, aneurysm formation, and rupture. Radiology 225:78-82

68. Jinzaki M, Silverman SG, Akita H, Nagashima Y, Mikami S, Oya M (2014) Renal angiomyolipoma: a radiological classification and update on recent developments in diagnosis and management. Abdom Imaging 39:588-604

69. Israel GM, Bosniak MA, Slywotzky CM, Rosen RJ (2002) CT differentiation of large exophytic renal angiomyolipomas and perirenal liposarcomas. AJR Am J Roentgenol 179:769-773

70. Wang LJ, Wong YC, Chen CJ, See LC (2002) Computerized tomography characteristics that differentiate angiomyolipomas from liposarcomas in the perinephric space. J Urol 167:490-493

71. Ellingson JJ, Coakley FV, Joe BN, Qayyum A, Westphalen AC, Yeh BM (2008) Computed tomographic distinction of perirenal liposarcoma from exophytic angiomyolipoma: a feature analysis study. J Comput Assist Tomogr 32:548-552

72. Khater N, Khauli R, Shahait M, Degheili J, Khalifeh I, Aoun J (2013) Solitary fibrous tumors of the kidneys: presentation, evaluation, and treatment. Urol Int 91:373-383

73. Morimitsu Y, Nakajima M, Hisaoka M, Hashimoto H (2000) Extrapleural solitary fibrous tumor: clinicopathologic study of 17 cases and molecular analysis of the p53 pathway. APMIS 108:617-625

74. Hasegawa T, Matsuno Y, Shimoda T, Hasegawa F, Sano T, Hirohashi S (1999) Extrathoracic solitary fibrous tumors: Their histological variability and potentially aggressive behavior. Hum Pathol 30:1464-1473

75. Gengler C, Guillou L (2006) Solitary fibrous tumour and haemangiopericytoma: evolution of a concept. Histopathology 48:63-74

76. Gold JS, Antonescu CR, Hajdu C et al (2002) Clinicopathologic correlates of solitary fibrous tumors. Cancer 94:1057-1068
77. Takizawa I, Saito T, Kitamura Y et al (2008) Primary solitary fibrous tumor (SFT) in the retroperitoneum. Urol Oncol 26:254 259

78. Casas JD, Balliu E, Sánchez MC, Mariscal A (2004) Benign solitary fibrous tumor of the retroperitoneum: radiological features. CMIG Extra: Cases 28:50-53

79. Fletcher CDM, Bridge JA, Hogendoorn P, Mertens F (2013) Desmoid-type fibromatoses.WHO Classification of Tumours of Soft Tissue and Bone. IARC

80. Kreuzberg B, Koudelova J, Ferda J, Treska V, Spidlen V, Mukensnabl P (2007) Diagnostic problems of abdominal desmoid tumors in various locations. Eur J Radiol 62:180-185

81. Dinauer PA, Brixey CJ, Moncur JT, Fanburg-Smith JC, Murphey MD (2007) Pathologic and MR imaging features of benign fibrous soft-tissue tumors in adults. RadioGraphics 27:173-187

82. Fiore M, MacNeill A, Gronchi A, Colombo C (2016) Desmoidtype fibromatosis: evolving treatment standards. Surg Oncol Clin N Am 25:803-826

83. Castellazzi G, Vanel D, Le Cesne A et al (2009) Can the MRI signal of aggressive fibromatosis be used to predict its behavior? Eur J Radiol 69:222-229

84. Kantorovich V, Pacak K (2010) Pheochromocytoma and paraganglioma. Prog Brain Res 182:343-373

85. Reisch N, Peczkowska M, Januszewicz A, Neumann HP (2006) Pheochromocytoma: presentation, diagnosis and treatment. J Hypertens 24:2331-2339

86. Pillai S, Gopalan V, Smith RA, Lam AK (2016) Updates on the genetics and the clinical impacts on phaeochromocytoma and paraganglioma in the new era. Crit Rev Oncol Hematol 100: 190-208

87. Brink I, Hoegerle S, Klisch J, Bley TA (2005) Imaging of pheochromocytoma and paraganglioma. Fam Cancer 4:61-68

88. Blake MA, Kalra MK, Maher MM et al (2004) Pheochromocytoma: an imaging chameleon. RadioGraphics 24: S87-S99

89. Castinetti F, Kroiss A, Kumar R, Pacak K, Taieb D (2015) Imaging and imagingbased treatment of pheochromocytoma and paraganglioma. Endocr Relat Cancer 22:T135-T145

90. Santhanam P, Taieb D (2014) Role of (18) F-FDOPA PET/CT imaging in endocrinology. Clin Endocrinol (Oxf) 81:789-798

91. Rha SE, Byun JY, Jung SE, Chun HJ, Lee HG, Lee JM (2003) Neurogenic tumors in the abdomen: tumor types and imaging characteristics. RadioGraphics 23:29-43

92. Kumar AJ, Kuhajda FP, Martinez CR, Fishman EK, Jezic DV, Siegelman SS (1983) Computed tomography of extracranial nerve sheath tumors with pathological correlation. J Comput Assist Tomogr 7:857-865

93. Pilavaki M, Chourmouzi D, Kiziridou A, Skordalaki A, Zarampoukas T, Drevelengas A (2004) Imaging of peripheral nerve sheath tumors with pathologic correlation: pictorial review. Eur J Radiol 52:229-239

94. Chee DW, Peh WC, Shek TW (2011) Pictorial essay: imaging of peripheral nerve sheath tumours. Can Assoc Radiol J 62:176-182

95. Motzer RJ, Jonasch E, Agarwal N et al (2015) Kidney cancer, version 3.2015. J Natl Compr Cancer Netw 13:151-159

96. Escudier B, Porta C, Schmidinger M et al (2016) Renal cell carcinoma: ESMO clinical practice guidelines for diagnosis, treatment and follow-up. Ann Oncol 27:v58-v68

97. Muglia VF, Prando A (2015) Renal cell carcinoma: histological classification andcorrelation with imaging findings. Radiol Bras 48:166-174

98. Eble JN, Sauter G, Epstein JI, Sesterhenn IA (2004) World Health Organization Classification of Tumours. Pathology and genetics of tumours of the urinary system and male genital organs. IARC Press, $\mathrm{p}$ 10-87 
99. Lipworth L, Morgans AK, Edwards TL et al (2016) Renal cell cancer histological subtype distribution differs by race and sex. BJU Int 117:260-265

100. Novara G, Ficarra V, Antonelli A et al (2010) Validation of the 2009 TNM version in a large multi-institutional cohort of patients treated for renal cell carcinoma: are further improvements needed? Eur Urol 58:588-595

101. Gurel S, Narra V, Elsayes KM, Siegel CL, Chen ZE, Brown JJ (2013) Subtypes of renal cell carcinoma: MRI and pathological features. Diagn Interv Radiol 19:304-311

102. Low G, Huang G, Fu W, Moloo Z, Girgis S (2016) Review of renal cell carcinoma and its common subtypes in radiology. World J Radiol 8:484-500

103. Choyke PL, Glenn GM, Walther MM, Zbar B, Linehan WM (2003) Hereditary renal cancers. Radiology 226:33-46

104. Zhu J, Yang Z, Tang G, Wang Z (2015) Extragastrointestinal stromal tumors: computed tomography and magnetic resonance imaging findings. Oncol Lett 9:201-208

105. Casella C, Villanacci V, D’Adda F, Codazzi M, Salerni B (2012) Primary extragastrointestinal stromal tumor of retroperitoneum. Clin Med Insights Oncol 6:189-197

106. Watal P, Brahmbhatt SG, Thoriya PJ, Bahri NU (2014) Retroperitoneal extragastrointestinal stromal tumor: radiologic pathologic correlation. J Clin Imaging Sci 41
107. Wilbur AC, Turk JN, Capek V (1992) Perirenal metastases from lung cancer: CT diagnosis. J Comput Assist Tomogr 16:589-591

108. Moulis G, Sailler L, Bonneville F, Wagner T (2014) Imaging in Erdheim-Chester disease: classic features and new insights. Clin Exp Rheumatol 32:410-414

109. De Filippo M, Ingegnoli A, Carloni A et al (2009) ErdheimChester disease: clinical and radiological findings. Radiol Med 114:1319-1329

110. Antunes C, Graça B, Donato P (2014) Thoracic, abdominal and musculoskeletal involvement in Erdheim-Chester disease: CT, MR and PET imaging findings. Insights Imaging 5:473-482

111. Mantilla JG, Goldberg-Stein S, Wang Y (2016) Extranodal RosaiDorfman disease: clinicopathologic series of 10 patients with radiologic correlation and review of the clinicopathologic series of 10 patients with radiologic correlation and review of the literature. Am J Clin Pathol 145:211-221

112. Foucar E, Rosai J, Dorfman R (1990) Sinus histiocytosis with massive lymphadenopathy (Rosai-Dorfman disease): review of the entity. Semin Diagn Pathol 7:19-73

113. Karaosmanoğlu AD, Onur MR, Shirkhoda A, Ozmen M, Hahn PF (2015) Unusual benign solid neoplasms of the kidney: cross-sectional imaging findings. Diagn Interv Radiol 21:376-381

114. Brown WE, Coakley FV, Heaney M (2002) Renal involvement by Rosai-Dorfman disease: CT findings. Abdom Imaging 27:214 216 